\title{
Teachers Matter: Feelings of School Connectedness and Positive Youth Development among Coos County Youth
}

\author{
NENA F. STRACUZZI AND MEGHAN L. MILLS
}

$\mathrm{D}$ uring the average school year, American youth spend about a quarter of their waking hours in school, most of it in the classroom, giving rise to its potential as a powerful context for influencing young people. ${ }^{1}$ Much research has examined the relationship between school climate and student outcomes, documenting, for example, the extent to which students tend to perform better academically, have better socio-emotional health, use fewer substances, and participate less in violent, aggressive, and bullying behaviors as a consequence of a positive school climate. In this brief, we focus on the extent that students feel connected, which may be one of the most important characteristics of school climate. $^{2}$

The Centers for Disease Control and Prevention (CDC) defines school connectedness as "the belief held by students that the adults and peers in their school care about their learning as well as about them as individuals." ${ }^{3}$ In other words, school connectedness is described as feeling positively about education, feeling a sense of belonging in the school environment, and having positive relationships with school staff and other students. The CDC reports that students who feel connected to school are more likely to have a number of positive health and academic outcomes. Research indicates that those students who report a high sense of school connectedness are less likely to use substances or engage in sexual intercourse; carry weapons; engage in violent or risk-taking behaviors, such as drinking and driving or not wearing seat belts; have emotional problems; suffer from eating disorders; or have suicidal thoughts. ${ }^{4}$

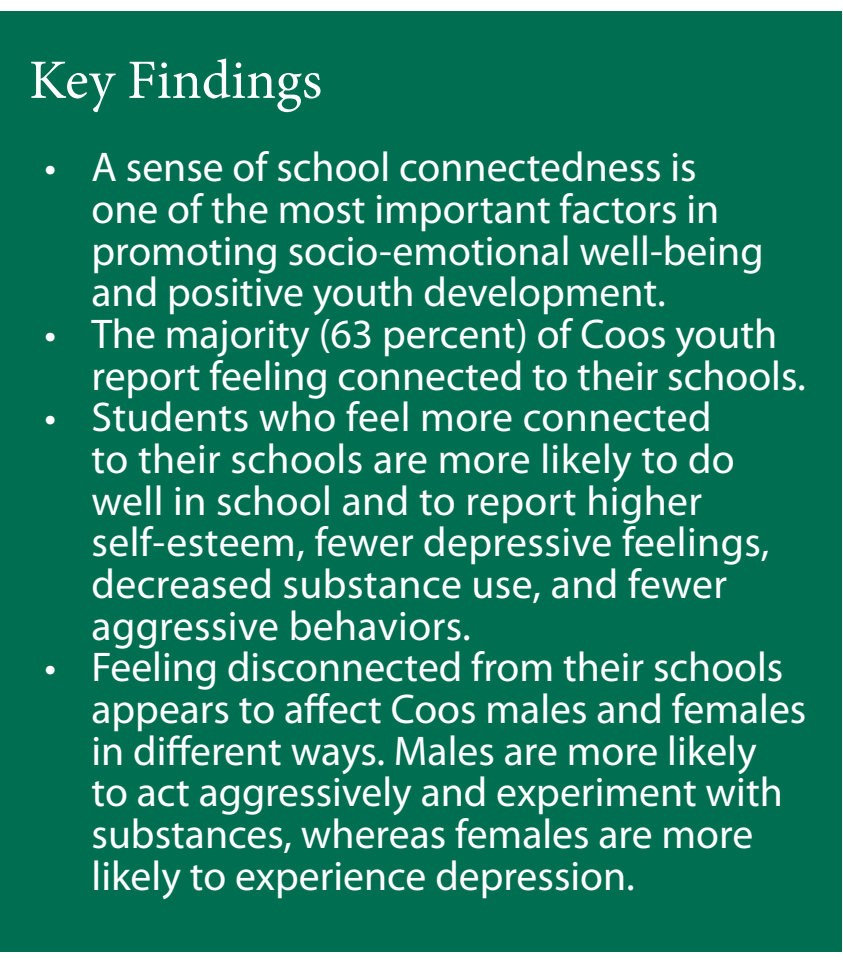

Developing a greater understanding of school connectedness and the extent to which it affects student outcomes may be particularly important for rural youth, given that they more often report feeling a sense of loneliness or isolation as compared to their urban counterparts. ${ }^{5}$ Rural youth may also 
be at greater risk of negative socio-emotional well-being as compared to urban youth. ${ }^{6}$

Research indicates that rural youth often lag behind their urban counterparts in academic achievement and are less likely to graduate high school. ${ }^{7}$ In addition, rural youth abuse substances, including alcohol and tobacco, at higher rates and at younger ages than urban youth. ${ }^{8}$ Although school connectedness is clearly important for all youth, very little research to date has examined school connectedness among rural youth.

We therefore analyze data on two groups of rural New Hampshire youth, collected as part of a longitudinal research project at the Carsey Institute. This data includes a number of questions that tap into youths' feelings of school connectedness and a number of socio-emotional outcomes. Given the current economic conditions in Coos County as residents are confronted with increased poverty and unemployment along with a subsequent diminishing population of young adults, it may be especially important that students feel connected at school.

The results described here are based on 2008 data, which was collected from 657 students that were fairly evenly divided by grade ( 48 percent seventh graders, 52 percent eleventh graders) and sex (50 percent female). For this brief, we combined data from the seventh-and eleventh-grade cohorts. The majority of the students in the sample were Caucasian (93 percent), most are native to Coos County (61 percent) and just about half live with married parents (53 percent). Ten percent of youths' fathers and 27 percent of their mothers hold at least a bachelor's degree.

The main purpose of this brief is to examine the relationship between Coos County youth's perceptions of school connectedness and their academic performance and socio-emotional well-being. Academic performance will be measured by students' self-reported grades, and socio-emotional well-being will be measured by self-esteem, depressive feelings, substance use, and delinquent behaviors. We will conclude with implications for policy makers and school practitioners regarding the importance of school connectedness and strategies for strengthening it among students.

\section{How Connected Do Coos Youth Feel to their Schools?}

We asked students the extent to which they agreed or disagreed with eleven statements regarding how connected they felt toward their schools, peers, and teachers. Response choices ranged on a scale from 0 , "strongly disagree," to 6 , "strongly agree." As shown in Figure 1, a slim majority of students agree with nearly all of the statements, indicating an overall strong sense of school connectedness. In particular, 61 percent agree that their teachers would be willing to help them with a personal problem and that students in class enjoy being together, and 62 percent agree that other students accept them as they are.

\section{FIgURE 1. SCHOOL CONNECTEDNESS}

Teacher Support

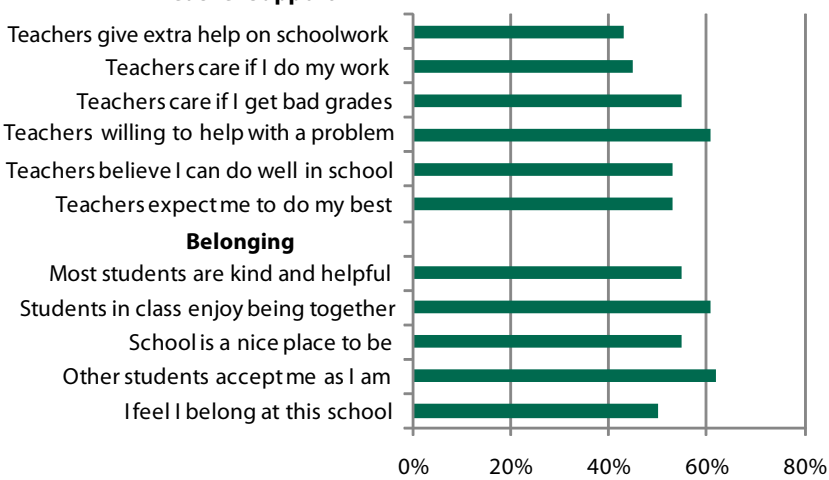


Two Dimensions of Connectedness: Teacher Support and School Belonging

School connectedness is composed of three key dimensions: social support, belonging, and engagement. ${ }^{9}$ Examining each dimension separately can provide policy makers and practitioners with a clearer understanding of the relationship between school connectedness and positive student outcomes..$^{10}$ This brief focuses on two key dimensions of school connectedness-students' perceptions of teacher support and his or her sense of belonging. Teacher support is based on the extent to which a student feels close to and valued by his or her teachers and other school staff. It is most commonly measured by whether students report his or her teachers like them, they care what their teachers think, they are comfortable talking to their teachers, and their teachers often praise them. ${ }^{11}$

The second dimension of school connectedness, sense of belongingness, is defined as a student's sense of being part of his or her school. Measures of belongingness often include the degree to which students feel they are respected at their school, belong to or are a part of their school, feel people at their school care about them, and have friends at their school. ${ }^{12}$ Throughout this brief, items for all measures of teacher support, school belonging, and socio-emotional well-being were combined to create a scale and then dichotomized at their means to indicate the degree to which student scores are above or below the average score.

Student responses are evenly divided, with 56 percent of students reporting they perceive their teachers care about them and 57 percent reporting they feel a sense of belonging. In Figure 2, however, we see results from further analyses demonstrating these are not necessarily the same students reporting equally on both measures. In fact, students who perceive they have teachers who care about them are significantly more likely to report feeling a sense of school belonging (63 percent) than are their counterparts (38 percent). ${ }^{13}$ Consistent with previous research, these findings suggest that students with teachers whom they perceive as supportive and sensitive to their needs are more likely to be engaged in school and feel a sense of belonging. ${ }^{14}$

Figure 2. STUdents' SENSE OF BELONGING By TEACHER SUPPORT $^{\star * *}$

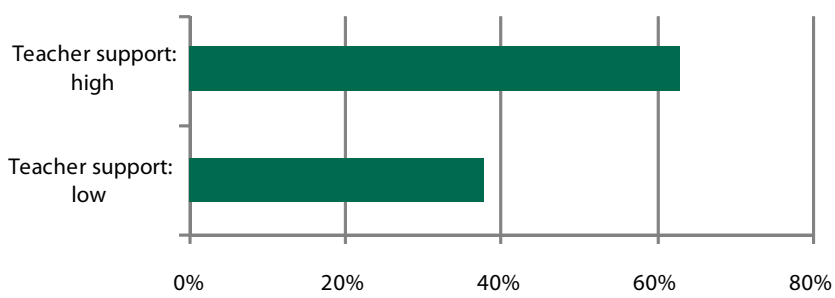

\section{Impacts of School Connectedness: Academic Performance}

As one might imagine, the most obvious positive outcome of school connectedness is academic performance. As Figures 3 and 4 show, those students who feel a sense of school connectedness also tend to perform better academically. ${ }^{15}$ More than half (57 percent) of students who reported a high level of teacher support received above average grades compared with only 45 percent of students who reported a low level of teacher support. Similarly, students who reported a high sense of belonging were more likely than students who reported a low sense of belonging to report earning all As and Bs (63 percent versus 38 percent). In all cases, differences are statistically significant. These findings are consistent with other research, showing that students who report a higher level of school connectedness are more likely to receive higher grades, achieve higher test scores, and graduate from high school, often because they are more likely to be engaged with their own education, motivated to do well, and enjoy learning. ${ }^{16}$ On the other hand, findings have demonstrated that those students who report feeling disconnected to their schools have higher truancy rates and are more likely to drop out of school. ${ }^{17}$

Figure 3. STUdents' GRADES BY PERCEPTION OF TEACHER SUPPORT ${ }^{* *}$

Teacher support: high

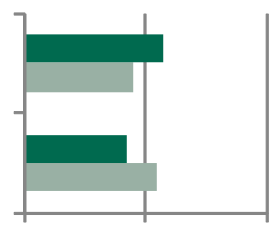

- Grades: above average

Teacher support: low

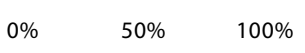

Grades: below average

Figure 4. STUdENTS' GRADES BY SENSE OF BELONGING ${ }^{* * *}$

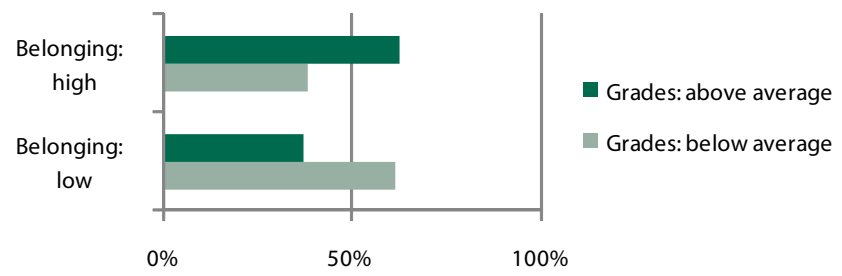




\section{Impacts of School Connectedness: Socio-Emotional Well-Being}

Research has found that not only does school connectedness have positive effects on academic achievement, but high levels of school connectedness are also associated with positive socio-emotional well-being. ${ }^{18}$ Although a difficult term to define, socio-emotional well-being is "the ability to successfully, resiliently, and innovatively participate in the routines and activities deemed significant by a cultural community" 19 In other words, positive socio-emotional well-being refers to the presence of positive psychological, physical, and social outcomes. ${ }^{20}$ For the purposes of this brief, we measure socioemotional well-being by both students' emotional internalizing behaviors, including self-esteem and depression, and their externalizing or social behaviors, including substance use and delinquent behaviors. We examine measures of both internalizing and externalizing behaviors because males and females often express or display negative socio-emotional well-being in different ways; when faced with traumatic events or a stressful situation, males are more likely to externalize these feelings through acts such as substance use and delinquency, whereas females are more likely to internalize these feelings, resulting in lower self-esteem and higher rates of depression. ${ }^{21}$

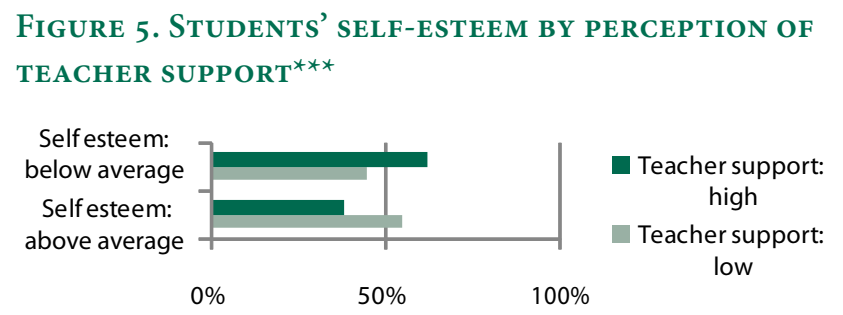

\section{Socio-Emotional Well-Being: Self-Esteem}

According to M. Rosenberg, self-esteem is a positive or negative orientation toward oneself, an overall evaluation of one's worth or value. We measure self-esteem by four items derived from the ten-item Rosenberg Self-Esteem Scale. ${ }^{22}$ Figures 5 and 6 show the extent to which self-esteem is affected by whether students perceive that their teachers care about them or they feel a sense of belonging. Just over six in ten (62 percent) students who report high teacher support score above average on self-esteem. This compares with only 45 percent of students who report low teacher support (see Figure 5). Almost three-quarters (69 percent) of students with a high sense of belonging score above average on self-esteem compared with less than one-third (31 percent) who score below average (see Figure 6). These results support other research in suggesting that both the quality of the student-teacher relationship and a sense of belonging are important for students' self-esteem. ${ }^{23}$ It is not surprising that self-esteem is affected when students more readily feel that their teachers and peers respect and value them for who they are. ${ }^{24}$ Contrary to current national research that indicates females typically have lower self-esteem than males, ${ }^{25}$ we find no significant gender differences among Coos County students.

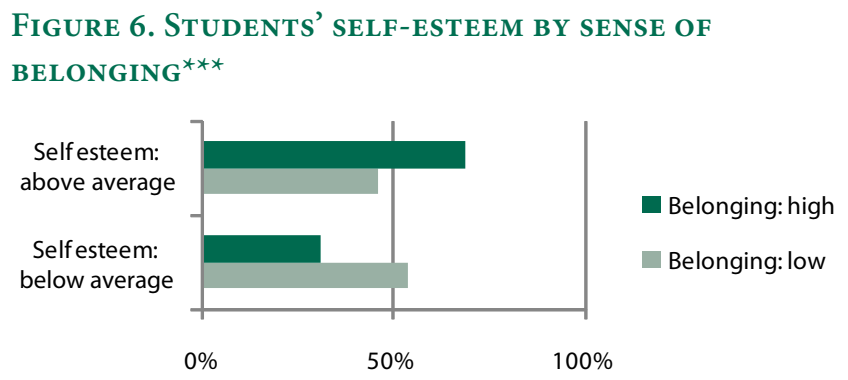




\section{Socio-Emotional Well-Being: Depressive Feelings}

We measure depressive feelings with seven items from the twenty-item Center for Epidemiologic Studies Depression Scale (CES-D). This scale, used by the National Institute of Mental Health, is one of the most common self-report screening tests used to measure depressive feelings. This scale is not a clinical diagnoses of depression but rather a measure of some depressed feelings that students might be having. ${ }^{26}$ Figures 7 and 8 show the extent to which students' depressed feelings are affected by whether they perceive that their teachers care about them or they feel a sense of belonging. Figure 7 shows that among those students who score above average on depressed feelings, only 48 percent report a high level of teacher support. This compares with 58 percent of students who report a low level of teacher support. In

FIGURE 7. STUDENTS' DEPRESSIVE FEELINGS BY

\section{PERCEPTION OF TEACHER SUPPORT}

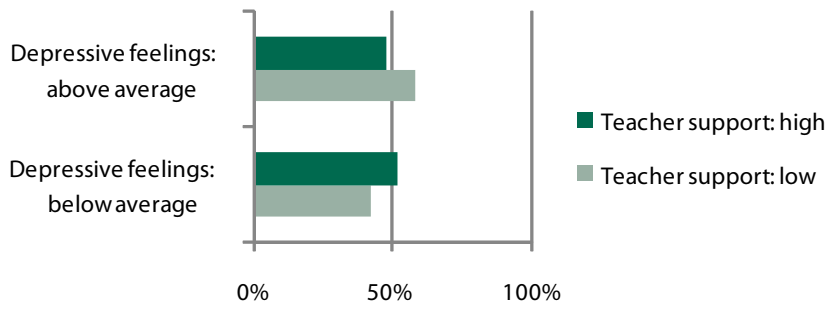

other words, the more students feel their teacher's care about them, the fewer depressed feelings they report. Similarly, in Figure 8, only 42 percent of those who score above the average on depressed feelings report a high sense of belonging, compared with 69 percent whose sense of belonging is low.

This is consistent with research that finds teacher behavior that values students' needs and perspectives coupled with a student's greater perceived school belonging, resulting in fewer depressive feelings among high school students. ${ }^{27}$ In addition, when students are more connected to their schools and teachers, they are more likely to be familiar with and have access to coping strategies and resources to more effectively deal with stressful situations and problems that may have otherwise led to depressive feelings. ${ }^{28}$ Also consistent with national research, we find significant gender differences in depressive feelings among Coos students-females are more likely than males to report experiencing depressive symptoms. ${ }^{29}$

FIGURE 8. STUDENTS' DEPRESSIVE FEELINGS BY SENSE OF BELONGING***

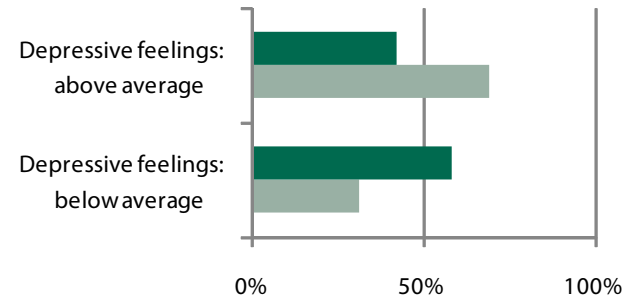

Belonging: high

Belonging: low 


\section{Socio-Emotional Well-Being: Substance Use}

We assessed substance use with the following question: "In the past 6 months only, how often have you used each of the following substances for non-medical reasons (such as for kicks, to get high, to feel good, or because you were curious)." ${ }^{30}$ Figure 9 shows significant differences by teacher support, with higher scores on substance use linked to lower teacher support. Specifically, among those students who report above average use, 37 percent report high teacher support. This compares with 56 percent of students who report low teacher support. Similarly, Figure 10 shows higher scores on substance use are related to a lower sense of belonging. Students whose sense of belonging is high report about 40 percent less substance use than do students whose sense of belonging is low. Hence, greater school connectedness is associated with decreased substance use among Coos students. This finding supports existing research that school connectedness protects against risky health behaviors among adolescents, especially substance use. ${ }^{31}$ When students have a strong bond to school, this connectedness may serve as a form of social control that reduces problem behaviors such as substance use and prevents students from associating with peers who use illicit substances. ${ }^{32}$ In addition, male Coos students are significantly more likely to report substance use, which corresponds with other findings that males are more likely than females to report using substances. ${ }^{33}$

Figure 9. STUdents' SUbSTANCE USE by PERCEPTION OF TEACHER SUPPORT ${ }^{* *}$
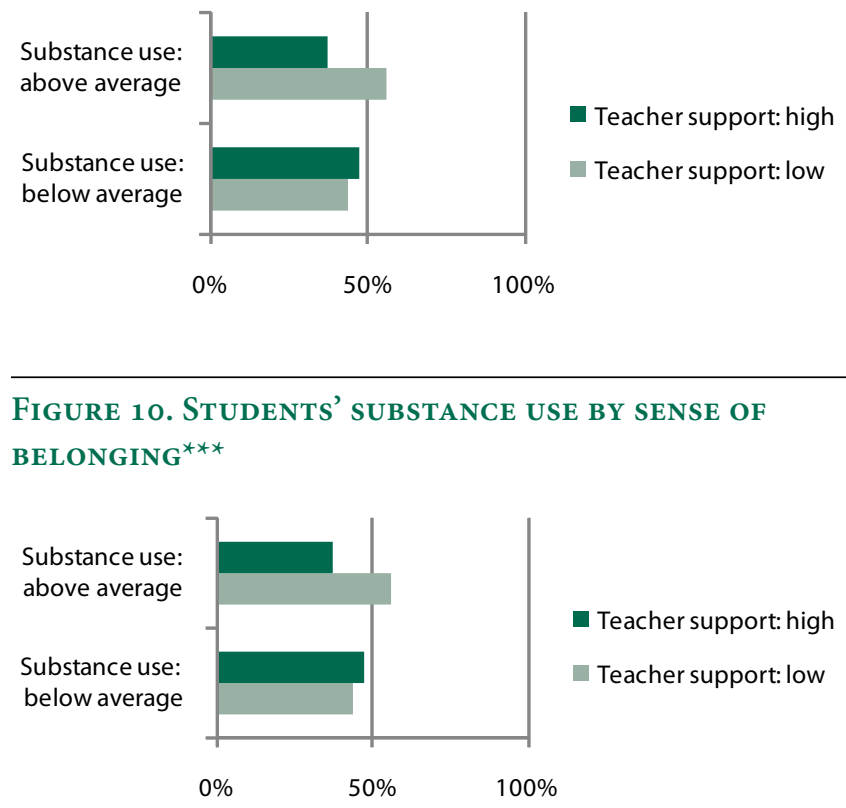

\section{Socio-Emotional Well-Being: Delinquent Behaviors}

We measured delinquency using a modified version of the Self-Report Delinquency (SDR) measure used in the National Youth Survey. ${ }^{34}$ We find that students' sense of school connectedness has a significant effect on delinquent behaviors, with those who feel a stronger sense of school connectedness engaging in fewer delinquent behaviors. Figure 11 shows that among those students who report high teacher support, only 43 percent scored above average on delinquent behaviors, compared to 57 percent who scored below average. Even more striking, Figure 12 shows that among those students whose sense of belonging is high, only 38 percent scored above average on delinquent behaviors, compared with 62 percent who scored below average. Therefore, consistent with other research on the topic, we found increased school connectedness decreases delinquency. ${ }^{35}$ Research suggests that when students feel a greater bond to their school, they are less likely to associate with delinquent peers or to be as susceptible to other negative influences. ${ }^{36} \mathrm{In}$ addition, Coos males are more likely than females to report engaging in delinquent behaviors, which also supports existing research. ${ }^{37}$

Figure 11. STUdents' DELINQUENT BeHAVIORS BY PERCEPTION BY TEACHER SUPPORT ${ }^{*}$

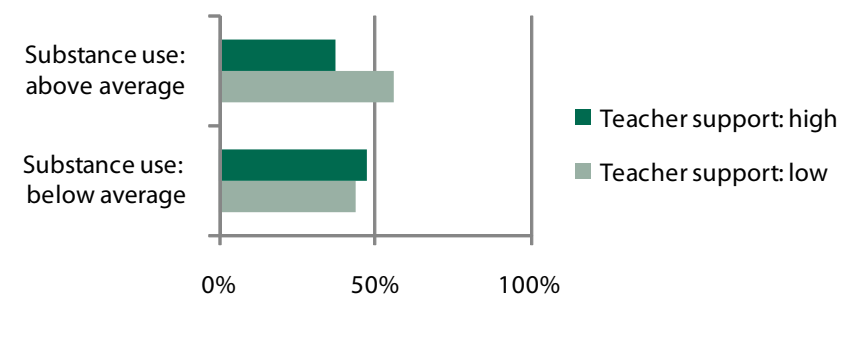

Figure 12. Students' delinquent Behaviors by SENSE OF BELONGING

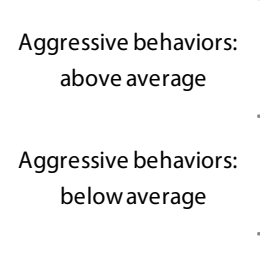

$0 \%$

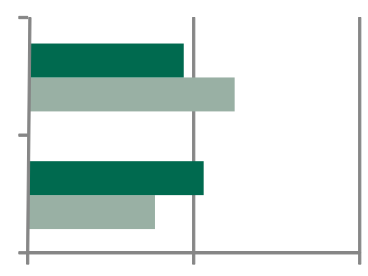

\% $\quad 50 \%$
Belonging: high Belonging: low 


\section{Conclusion}

Consistent with previous research, school connectedness, as measured by students' perceptions of teacher support and sense of school belonging, promotes positive socio-emotional well-being among Coos County youth. Those students who feel a greater sense of school belonging and have greater perceptions of teacher support are significantly more likely to perform better academically, have higher self-esteem, have fewer depressive feelings, use fewer substances, and engage in fewer delinquent behaviors. ${ }^{38}$ Our findings also support previous research that males and females respond differently to feelings of school disconnection. Males are more likely to report using substances and acting out with delinquent behaviors, whereas females are more likely to report depressive symptoms. Fortunately for Coos County youth, a majority of students reported feelings of school connectedness. We have also seen that students who perceive that their teachers care about them are more likely to feel a sense of school belonging. This is great news, as the majority of Coos students report a high sense of teacher support.

It is important for schools to reach out to the minority of students who feel disconnected from their schools and hence are at a greater risk for poor academic performance, low self-esteem, depression, substance use, and delinquent behaviors. Research indicates that teachers are the most important factor in promoting a positive school climate. ${ }^{39}$ Research regarding evidence-based best practices reveal that teachers can promote school connectedness through encouraging open communication with both students and parents and giving students an opportunity to express their own educational preferences. Teachers should also work to provide students with appropriate leadership, teamwork, and problem solving skills in an attempt to reduce teasing and bullying among students. Similarly, teachers can promote a sense of school connectedness by encouraging their students to work one on one with adults outside of the classroom through mentoring, service learning projects, or other extra-curricular activities. ${ }^{40}$
However, responsibility for improving school connectedness among students should not be placed solely on teachers. According to the National School Climate Counsel, it takes a "whole village" to support a greater sense of school connectedness and positive socio-emotional well-being among students. ${ }^{41}$ The $\mathrm{CDC}$ argues that the socio-emotional climate at school is influenced by such factors as discipline, opportunities for meaningful student participation, and classroom management practices. ${ }^{42}$ The CDC argues that greater school connectedness can be fostered by supporting youth academic achievement and staff empowerment, involving families in the academic success of their children, providing adequate training for teachers and other school staff, and most importantly "create[ing] trusting and caring relationships that promote open communication among administrators, teachers, staff, students, families, and communities." ${ }^{43}$ Similarly, the National School Climate Counsel suggests that policy makers, practitioners, and teachers all work together to ensure a clear understanding of what school connectedness is and to provide professional inservices and teacher preparation programs on how such connectedness can be practically implemented. They also suggest further examining the impact of best practices and their affect on school connectedness. ${ }^{44}$

Although it is clear that student perceptions of teacher support and school belonging play a crucial role in feeling connected to school and to socio-emotional well-being, numerous other factors also affect this relationship. As previous research has suggested, participation in extracurricular activities, student age, and school size may also affect the degree to which students feel connected to their schools. ${ }^{43}$ In fact, a recent study found that Coos County students who participated in more out-of-school activities were more likely to feel a stronger sense of school belonging and other indicators of positive youth development. ${ }^{44}$ As we continue to collect data from Coos County Youth, it will be crucial to further examine how school connectedness may change over time, which factors may increase this sense of connectedness, and how it affects youth's lives after high school. 


\section{E N D N O T ES}

1. R. Pianta, M. Stuhlman, and B. Hamre, "How Schools Can Do Better: Fostering Stronger Connections Between Teachers and Students," New Directions for Youth Development, 93 (2002): 91-107.

2. J. Cohen et al., "School Climate: Research, Policy, Teacher Education and Practice," Teachers College Record, 111 (1) (2009): 180-213.

3. Centers for Disease Control and Prevention. Fostering School Connectedness: Improving Student Health and Academic Achievement (Atlanta: Centers for Disease Control, 2009).

4. Centers for Disease Control and Prevention, Fostering School Connectedness.

5. Anastasa Snyder and Diane McLaughlin, "Rural Youth are More Likely to be Idle," Fact Sheet No. 11 (Durham, NH: Carsey Institute, University of New Hampshire, 2008).

6. Anthony Glendinning, et al., "Rural Communities and Well-Being: A Good Place to Grow Up?" Editorial, Sociological Review, (2003): 129-156.

7. U.S. Department of Agriculture, "Rural Education at a Glance," Rural Development Research Report No. 98 (Washington, DC: USDA, Economic Research Service, 2003); Vincent J. Roscigno and Martha L. Crowle, "Rurality, Institutional Disadvantage, and Achievement/Attainment," Rural Sociology, 66 (2) (2001): 268-292.

8. Karen Van Gundy, Substance Abuse in Rural and Small Town America, A Carsey Institute Report on Rural America (Durham, NH: Carsey Institute, University of New Hampshire, 2006); David Hartley, "Substance Abuse Among Rural Youth A Little Meth and a Lot of Booze," Research and Policy Brief (Maine: Muskie School of Public Service, 2007); Lisa Pruitt, "The Forgotten Fifth: Rural Youth and Substance Abuse," Stanford Law and Policy Review, 20 (2009): 101-148.

9. J. P. Connell and J. Wellborn, "Competence, Autonomy, and Relatedness: A Motivational Analysis of Self-System Processes," in Self Processes in Development: Minnesota Symposium on Child Development, edited by M. Gunnar and L. Sroufe (Hillsdale, NJ: Earlbaum, 1991), 43-77.

10. Clea A. McNeely and C. Falci, "School Connectedness and the Transition Into and Out of Health Risk Behavior among Adolescents: A Comparison of School Belonging and Teacher Support," Journal of School Health, 74 (7) (2004): 284-292.

11. Michael Resnick et al., "Protecting Adolescents from Harm: Findings from the National Longitudinal Study on Adolescent Health," Journal of the American Medical Association, 278 (10) (1997): 823-832; H. P. Libbey, "Measuring Student Relationships to School: Attachment, Bonding and Connectedness," The Journal of School Health, 74 (7) (2004): 274.
12. Kristin Voelkl, “Measuring Students' Identification with School," Educational and Psychological Measurement, 56 (1996): 760-770; Libbey, "Measuring Student Relationships to School."

13. Differences are significant at ${ }^{\star} \mathrm{p}<.05 ;{ }^{* *} \mathrm{p}<.01 ;{ }^{* * *} \mathrm{p}<.001$ and holds when controlling for parents' marital status, parents' education, ethnicity, sex, and age.

14. Adena M. Klem and James P. Connell, "Relationships Matter: Linking Teacher Support to Student Engagement and Achievement," Journal of School Health, 74 (7) (2004): 262-273; Maria D. LaRusso, Daniel Romer, and Robert L. Selman, "Teachers as Builders of Respectful School Climates: Implications for Adolescent Drug Use Norms and Depressive Symptoms in High School," Journal of Youth and Adolescence, 37 (4) (2008): 386-398.

15. Students' grades are self-reported. Response choices were (1) all As; (2) mostly As and Bs; (3) all Bs; (4) mostly Bs and Cs; (5) all Cs; (6) mostly Cs and Ds; (7) all Ds; (8) mostly Ds and Fs; or (9) all Fs.

16. Klem and Connell, "Relationships Matter"; W. Willingham, J. M. Pollack, and C. Lewis, "Grades and Test Scores: Accounting for Observed Differences," Journal of Educational Measures, 39 (1) (2002): 1-37; K. R. Wentzel, "Social Relationships and Motivation in Middle School," Journal of Educational Psychology, 90 (2) (1998): 202-209.

17. R. G. Croninger and V. E. Lee, "Social Capital and Dropping Out of High Schools: Benefits to At-Risk Students of Teachers' Support and Guidance," Teachers College Record, 103 (4) (2001): 548-581; J. P. Connell et al., "Hanging in There: Behavioral, Psychological, and Contextual Factors Affecting Whether African-American Adolescents Stay in School," Journal of Adolescent Research, 10 (1) (1995): 41-63.

18. Andrea Bonny et al., "School Disconnectedness: Identifying Adolescents at Risk," Pediatrics, 106 (5) (2000): 10171021; Clea McNeely, James M. Nonnemaker, and Robert W. Blum, "Promoting School Connectedness: Evidence from the National Longitudinal Study of Adolescent Health," Journal of School Health, 72 (4) (2002): 138-146; National School Climate Council, The School Climate Challenge: Narrowing the Gap Between School Climate Research and School Climate Policy, Practice Guidelines and Teacher Education Policy (New York: National School Climate Council, 2010); Cohen et al., "School Climate."

19. T. S. Weisner, "Human Development, Child Well-Being, and the Cultural Project of Development," New Directions for Child Development, 81 (1988): 69-85

20. Elizabeth Pollard and Patrice D. Lee Child, "Well-Being: A Systematic Review of the Literature," Social Indicators Research, 61 (1) (2003): 59-78. 
21. S. Rosenfield, "Splitting the Difference: Gender, the Self, and Metal Health," in Handbook of the Sociology of Mental Health, edited by C. S. Aneshensel and J. C. Phelan (New York: Kluwer Academic Press, 1999), 209-224.

22. Statements with which students were asked to agree or disagree are: (1) I have a number of good qualities; (2) I am able to do things as well as most other people; (3) I take a positive attitude toward myself; and (4) On the whole I am satisfied with myself. Response choices are on a four-point scale that range between " $0=$ strongly disagree," to " 3 = strongly agree." M. Rosenberg, Society and the Adolescent Self-Image (Princeton, NJ: Princeton University Press, 1965).

23. D. R. Hoge, E. K. Smit, and S. L. Hanson, "School Experiences Predicting Changes in Self-Esteem of Sixth and Seventh-Grade Students," Journal of Educational Psychology, 82 (1990): 117-127.

24. Bill Nave, "Self-Esteem: The Key to Student Success," (Clemson, SC: The National Dropout Prevention Center, December 1-6, 1990).

25. Rosenfield, "Splitting the Difference"; M. Polce-Lynch et al., "Adolescent Self-Esteem and Gender: Exploring Relationships to Sexual Harassment, Body Image, Media Influence, and Emotional Expression," Journal of Youth and Adolescence, 30 (2) (2001): 225-244; K. R. Puskar et al., "Self-Esteem and Optimism in Rural Youth: Gender Differences," Contemporary Nurse, 34 (2) (2010): 190-198.

26. Statements about which students were asked to respond are as follows: (1) I felt sad; (2) I couldn't get going; (3) I did not feel like eating; (4) My sleep was restless; (5) I felt depressed; (6) I felt fearful; and (7) I felt lonely. Response choices are on a four-point scale that range between " $0=$ not at all," to " $3=$ almost all the time," and students were asked how often in the past six months they had had each feeling.

27. LaRusso et al., "Teachers as Builders of Respectful School Climates."

28. R. W. Roeser, Jacquelynne S. Eccles, and A. J. Sameroff, "School as a Context of Early Adolescents' Academic and Social-Emotional Development: A Summery of Research Findings," Elementary School Journal, 100 (5) (2000): 443-471.

29. Benjamin Hankin et al, "Development of Depression from Preadolescence to Young Adulthood: Emerging Gender Differences in a 10-Year Longitudinal Study," Journal of Abnormal Psychology, 107 (1) (1998): 128-140; Rosenfield, "Splitting the Difference."

30. Substances included were alcohol, tobacco/cigarettes, marijuana/hashish, inhalants/whippets, uppers/speed, pills/ painkillers, and other drugs. Response choices range from "0 $=$ no times," to " $6=$ nearly every day."
31. McNeely and Falci, "School Connectedness and the Transition Into and Out of Health Risk Behavior among Adolescents."

32. Richard Catalano et al., "The Importance of Bonding to School for Health Development: Findings from the Social Development Research Group," Journal of School Health, 74 (7) (2004): 252-261.

33. Rosenfield, "Splitting the Difference"; Substance Abuse and Mental Health Services Administration, Results from the 2008 National Survey on Drug Use and Health: National Findings (Rockville, MD, 2009).

34. Students were asked how many times they had engaged in each of these twelve behaviors in the last six months: (1) taken something from a store without paying for it; (2) other than from a store, taken something not belonging to you; (3) intentionally damaged or destroyed someone's property that did not belong to you; (4) gotten into a physical fight at school; (5) gotten into a serious argument at school; (6) seriously hit someone (not a family member); (7) seriously threatened someone (not a family member); (8) seriously hit a family member; (9) seriously threatened a family member; (10) committed assault on anyone (a violent physical attack); (11) bullied someone (for example, made fun of, threatened, excluded, spread rumors or lies, made sexual or racist comments, and so on); (12) bullied someone via the Internet (online version of above). Students were asked simply to fill in the number of times they had engaged in each of these behaviors. Because this measure can be so skewed with most students never engaging in any of the behaviors and a few who report fairly extreme numbers, each item was dichotomized such that students are considered to either have engaged in a behavior or not, and then these dichotomous items were combined to create a scale. It is important to note that most students (56 percent) reported either engaging in none of the listed behaviors (39 percent) or just one (17 percent); Suzanne S. Ageton and Delbert S. Elliott, "Reconciling Race and Class Differences in Self-Reported and Official Estimates of Delinquency," American Sociological Review, 45 (1) (1980): 95-110.

35. Centers for Disease Control and Prevention, Fostering School Connectedness.

36. Dorian Wilson, "The Interface of School Climate and School Connectedness and Relationships with Aggression and Victimization," Journal of School Health, 74 (7) (2004): 293-299.

37. Rosenfield, "Splitting the Difference"; Katherine Karriker-Jaffe et al., "The Development of Aggression During Adolescence: Sex Differences in Trajectories of Physical and Social Aggression Among Youth in Rural Areas," Journal of Abnormal Child Psychology, 36 (2008): 1227-1236. 
38. Given that the analysis in this brief is based on only one wave of data (longitudinal data), the causal order of school connectedness and these socio-emotional outcomes can not be determined. In other words, we cannot say that school connectedness "causes" these outcomes, but only that there is a relationship between these two concepts. However, as more data are collected, we hope to be able to examine this relationship causally.

39. National School Climate Council, The School Climate Challenge; McNeely and Falci, "School Connectedness and the Transition."

40. National School Climate Council, The School Climate Challenge, McNeely, Nonnemaker, and Blum, "Promoting School Connectedness"; Centers for Disease Control and Prevention, School Connectedness: Strategies for Increasing Protective Factors Among Youth (Atlanta, GA: Centers for Disease Control, 2009).

41. National School Climate Council, The School Climate Challenge.

42. McNeely, Nonnemaker, and Blum, "Promoting School Connectedness"; Centers for Disease Control and Prevention, School Connectedness.

43. Centers for Disease Control and Prevention, School Connectedness.

44. National School Climate Council, The School Climate Challenge.

45. Centers for Disease Control and Prevention, School Connectedness.

46. Erin Sharp, “Out-of-School Time Matters: Activity Involvement and Positive Development among Coos County Youth.” Issue Brief No. 17 (Durham, NH: Carsey Institute, University of New Hampshire, 2010).

\section{A C K N O W L E D G M E N T S}

The Coos Youth Study team thanks the students who are participating in this research project and the superintendents, principals, guidance counselors, and administrators who helped the team collect the data. The authors would like to thank Jonathan Cohen, Erin Sharp, and Curt Grim for invaluable feedback on early versions of this brief.

\section{A B OUT THE AUTHORS}

Nena F. Stracuzzi is a Carsey Institute faculty fellow and lecturer in the Departments of Sociology and Justice Studies (nena.stracuzzi@unh.edu).

Meghan L. Mills is a doctoral candidate in sociology at the University of New Hampshire and a research assistant at the Carsey Institute (meghan.l.mills@unh.edu). 


\section{THE CARSEY INSTITUTE COOS YOUTH STUDY}

The Carsey Institute is conducting a panel study of Coos County youth that will provide data about the attitudes and experiences of the county's youth as they approach young adulthood and face the decision to remain in their community, seek opportunities elsewhere, or leave for an education and then return. By following the entire populations of two age groups over a ten-year period, we will help North Country leaders gain a better understanding of young people's decision making.

\section{RESEARCH TEAM}

Meghan L. MiLLS is a research assistant at the Carsey Institute and a doctoral student in sociology at the University of New Hampshire. Her research focuses on mental health and substance abuse.

Cesar Rebellon is a faculty fellow at the Carsey Institute and an associate professor in the Department of Sociology at the University of New Hampshire. His primary research interests focus on family and peer correlates of juvenile crime and delinquency, with a particular emphasis on the manner in which delinquency may yield reinforcing social rewards among adolescents.

ERIN Hiley Sharp is a Carsey Institute faculty fellow and assistant professor in the Department of Family Studies at the University of New Hampshire. Her research interests include activity involvement as a context for adolescent development; parental, family, and broader contextual influences on adolescent development; and prevention research and theory from a positive youth development perspective.

Nena Stracuzzi is a faculty fellow at the Carsey Institute and a faculty member in both the Department of Sociology and Justice Studies at the University of New Hampshire. Her research for the Carsey Institute has focused primarily on vulnerable youth and families.

Corinna Jenkins Tucker is a faculty fellow at the Carsey Institute and an associate professor in the Department of Family Studies at the University of New Hampshire. Her primary research interests focus on the nature and context of family relationships and their links to adolescent psychosocial development.

Heather Turner is a senior fellow at the Carsey Institute and a professor in the Department of Sociology at the University of New Hampshire. Her research concentrates on social stress processes and mental health.

KAREN VAN GUNDY is a faculty fellow at the Carsey Institute and an associate professor in the Department of Sociology at the University of New Hampshire. Her work investigates the mechanisms by which life circumstances and social statuses influence variations in health, emotional, and behavioral outcomes. 


\section{$\triangle$ UNIVERSITY - of NEW HAMPSHIRE}

\section{CARSEY \\ I N S T I T U T E}

Building knowledge for families and communities

The Carsey Institute conducts policy research on vulnerable children, youth, and families and on sustainable community development. We give policy makers and practitioners timely, independent resources to effect change in their communities.

Carsey Institute Reports on Tracking Change in the North Country are supported by the Neil and Louise Tillotson Fund at the New Hampshire Charitable Foundation and the Carsey Institute endowment.

Huddleston Hall

73 Main Street

Durham, NH 03824

(603) $862-2821$

www.carseyinstitute.unh.edu 